\title{
Analysis of Public Choice on Environmental Health Management: The Case of Dengue Fever Control in Kandy District
}

\author{
K.S.D. Siriwardena and L.H.P. Gunaratne ${ }^{*}$
}

\begin{abstract}
Dengue has become a major environmental health issue in Sri Lanka. Although many programmes have been implemented, yet a remarkable success has not been achieved mainly due to lack of cooperation from the public. In this study, the public choice on dengue control strategies was studied. The study was conducted in Kandy Municipality area, which has the highest risk of dengue in the Kandy district. A choice experiment was carried out with four environmental management attributes with three levels each. The attributes included were: improved cleaning, infrastructure provision, motivation of the public to continue control activities and willingness to pay for dengue control. A multinomial logit model (MNL) was estimated and the analysis revealed that people prefer improved cleaning by the neighbours in surroundings and provision of efficient water supply as effective strategies for dengue control. Furthermore, motivation strategies, which included larger spot fines, appeared to be important.
\end{abstract}

Keywords: Dengue fever, environmental management, choice experiment, public choice

\section{Introduction}

Environment is a key factor that determines the human health. As United Nations Environment Programme (UNEP) stated, the damaged, altered and degraded environment shifts natural balance, thereby triggers the spread of new and existing diseases to people while intact habitats and landscapes tend to keep the infectious diseases agents in check (United Nations Environment Programme, 2005). At present, infectious and vector borne diseases have become a high priority and key environment related public health issue. Among them, dengue fever has become one of the most important, especially in urban areas. Of many strategies adopted to control dengue, vector control to eradicate existing and possible larval breeding habitats is the most effective option available and this is only possible with

Authors are, respectively, Temporary Assistant Lecturer and Senior Lecturer, Department of Agricultural Economics and Business Management, Faculty of Agriculture, University of Peradeniya, Sri Lanka. 
the proper environmental management (National Plan of Action of Ministry of Health for 2005-2009, 2006).

As in many other countries, Dengue fever has become the most important mosquito-borne disease in Sri Lanka. Though, mortality (rate of deaths) has fluctuated a marked increase in morbidity (rate of illness) has been observed during past few years. In Sri Lanka, increased use of non-bio degradable plastics and polythene with poor disposal systems, lack of coordination and cooperation among public health authorities and local government institutions, poor response and participation of the community to keep their compounds free of mosquito breeding places and rapid urbanization with poor adherence to health concerns, refuse disposal and other sanitary measures have been identified as possible reasons to increase disease incidence (National Plan of Action 2005-2009, 2006).

As indicated in the National Plan of Action 2005-2009, 2006, it is always emphasized the necessity of an effective and integrated effort at national, regional, community and household levels for a sustainable prevention of dengue. Strategies like disease, vector and laboratory surveillance, clinical management of dengue cases, vector control and social mobilization for preventive activities are adopted. Despite many programmes, campaigns and projects implemented, a sustainable prevention and control has not been achieved yet, mainly due to lack of public cooperation. People have trade-offs among various strategies that can be implemented for dengue prevention. Some believe the necessity of an integrated prevention effort at national, regional, community and household levels while others feel that it is the responsibility of the local health institutions to take necessary actions to prevent dengue. Meanwhile another group especially in urban areas indicates that it is difficult for them to participate in preventive activities, but they are willing to pay for campaigns implemented by the others. On the other hand, most of these programmes have been developed giving less consideration to public choice. Therefore, it seems, the public is reluctant to give their cooperation to these programmes; as a consequence, the intended benefits cannot be achieved. Therefore, it is of paramount importance to analyze people's choice on dengue prevention through environmental management.

Against this background, the main objective of this study is to analyze the trade-offs among various dengue management strategies as perceived by the public in the Kandy municipality. The other objectives include identification of environmental management strategies for dengue control that the public prefer and estimation of the value people put on possible improvements in those strategies. 


\section{Methods and Materials}

\section{Conceptual Framework}

The success of the health care programmes already in operation depends on individual decisions about whether to take part in those, so that such programmes should be designed to meet consumer preferences (Louviere et al., 2004). Therefore, individual preferences must be identified prior to implementation, but this is not always possible. On the other hand, health care is highly regulated. Price signals do not indicate valid information about social costs and benefits or resource allocation (Louviere et al., 2004). Stated Preference methods are useful tools to investigate individual decision making on value of non-market good/service (health care). These methods are associated with the elicitation of responses of individuals to given alternatives in a hypothetical setting in the form of choices, ratings or ranking (Gunatilake, 2003).

Choice experiment (CE) is one of the stated preference methods which comes under attribute-based methods. Choice experiment was originally developed in the market and transport literature, but now has become familiar in environmental economics (Adamowicz et al., 1994; Adamowicz et al., 1998; Boxall and Adomowicz, 2002). Choice experiments are closely linked to two economic theories known as Lancaster's Characteristics theory of value (Lancaster, 1966) and the Random Utility theory (Thurstone, 1927; McFadden, 1973). In Choice experiments, respondents are presented with a series of alternative profiles of environmental goods or policies and asked to choose their most preferred choice (Bateman et al., 2002). These profiles are set out in terms of the attributes (characteristics) of these goods and policies (Hanley, et al., 2002). Usually a monetary value is included as one attribute. Factorial designs are used to generate orthogonal profiles. Fractional factorial designs can be used to reduce the number of profiles, thereby to reduce the cognitive burden faced by the respondents in the choice experiment (Holmes and Adamowicz, 2003). Since choice experiment values are relative, to transform them into absolute values which are useful in cost benefit analysis, a base line alternative corresponding to status quo and representing the 'do nothing' status is usually included in choice sets. The 'out put' of the CE technique gives estimates of compensating and equivalent surplus (Bateman et al., 2002). Also they allow for different changes in environment quality as well as differences in socio economic characteristics when transferring benefit estimates (Morrison et al., 2002).

Assuming that an individual's preference can be represented as a function, each choice (alternative) is represented with an indirect utility 
function. The utility function consists of an observable deterministic or systematic part $(\mathrm{V})$ and an unobservable stochastic or random element $(\varepsilon)$. Therefore the indirect utility function of $i^{\text {th }}$ individual for the $j^{\text {th }}$ alterative can be represented as

$$
U_{i j}=V_{i j}+\varepsilon_{i j}
$$

The individual would choose the alternative $\mathrm{j}$ in the choice set to any alternative $k$, if $U_{i j}>U_{i k}$

Since the utilities include a random element, predictions cannot be made with certainty. Thus, analysis becomes one of the probabilistic choices (Bateman et al., 2002). The probability of choosing the alternative $\mathrm{j}$ over $\mathrm{k}$ can be expressed as

$$
P\left[\left(U_{i j}>U_{i k)} \forall k \neq j\right]=P\left[\left(V_{i j}-V_{i k}\right)>\left(\varepsilon_{i k}-\varepsilon_{i j}\right)\right.\right.
$$

McFadden (1973) showed that if error term in the equation (2) is independently and identically distributed (IID) with a type one extreme value (Gumble distribution) the probability of any alternative $\mathrm{j}$ being chosen as the most preferred can be expressed in terms of the logistic distribution. This model is known as Conditional logit model or Multinomial logit (MNL) model (Bateman et al., 2002).

$$
P\left[\left(U_{i j}, U_{i k}\right) \forall k \neq j\right]=\frac{\exp \left(\mu V_{i j}\right)}{\sum_{j} \exp \left(\mu V_{i k}\right)}
$$

Here, $\mu$ is a scale parameter which is inversely proportional to the variance of the error term. MNL model can be estimated by maximum likelihood procedures, with the respective log- likelihood function (Bateman, et al., 2002).

$$
\log L=\sum_{i=1}^{n} \sum_{j=1}^{j} Y_{i j} \log \left[\frac{\exp \left(V_{i j}\right)}{\sum_{j=1}^{J} \exp \left(V_{i j}\right)}\right]
$$

Where $Y_{\mathrm{ij}}$ is an indicator variable which takes a value of one if $\mathrm{i}^{\text {th }}$ respondent choice of $j^{\text {th }}$ option and zero otherwise. The MNL model is usually specified as being linear in parameters and socio-economic variables can be included along with the choice set attributes in the systematic part of the 
model allowing for interactions since they are constant for each choice that any individual makes (Bateman et al., 2002).

$$
W T P=b_{y}^{-1} \ln \left[\frac{\sum_{i} \exp \left(V_{i}^{1}\right)}{\sum_{i} \exp \left(V_{i}^{0}\right)}\right]
$$

The equation (5) gives the Willingness to Pay (WTP) welfare measure for a given policy change that affect on the environmental good. The coefficient $b_{y}$ is the coefficient of the monetary attribute and $\mathrm{V}_{i}^{1}$ and $\mathrm{V}_{i}^{0}$ represent the utility of the initial state and alternative state respectively (Bateman et al., 2002). For linear utility index the above equation can be written as

$$
\mathrm{WTP}=-b_{\mathrm{c}} / b_{\mathrm{y}}
$$

where $b_{c}$ is the coefficient of any of the attributes and $b_{y}$ is the coefficient of the monetary attribute (Bateman et al., 2002).

\section{Methodology}

The study was carried out in the Kandy Municipality area which has the highest number of dengue cases reported in the Kandy district. Climate and land use play a significant role in dengue transmission. Major risk areas are located in densely populated urbanized areas, where most preferred vector breeding places are available. The survey was carried out during the $31^{\text {st }}$ of January to $10^{\text {th }}$ of February 2007. Using Stratified Random sampling technique, the GN divisions from where dengue cases were reported in the year 2006 were first identified and then six GN divisions (Mahaiyyawa, Suduhumpola Bowala, Mawilmada, Galewatta and Aruppala) were randomly selected. Sixty four households were sampled randomly among selected GN divisions in proportion to the number of household units in each GN division.

An in-house survey was carried out through a face-to-face interview. An interview schedule was designed to get the information on the socioeconomic background and the general attitude of the respondents towards the health issues and along with that a choice experiment was carried out. The choice experiment concerned the environment management strategies for dengue control. As depicted in Table 1, environmental management was attributed by three management strategies and willingness to pay (WTP) of the respondents for dengue control. Each attribute had three levels. These attributes and levels were identified by direct questioning from public, 
literature and focus group discussions with the health personnel. Of the 81 possible alternatives, nine were chosen using a fractional factorial design. Four choice sets each containing two alternatives (choice A and choice B) were obtained and presented as a pair. Table 2 shows a sample choice set used in the study. In the choice experiment, each respondent was presented with the four choice sets in a series. For each choice set, they were asked to choose between three options (choice A, choice B or Neither). The choice experiment was introduced with a description and explanation about the attributes in order to facilitate understanding the choice set. All the attributes in three levels were included in the analysis using the effect codes (Holmes and Adamowicz, 2003) and a multinomial logit model was estimated.

The model estimates are derived for L-1 levels where $\mathrm{L}$ is the number of levels of a given attribute in the design. To identify marginal utilities for all the levels in the experimental design, coefficients for the each attribute level redundant in the analysis were calculated, using the coding system used in the analysis. Parameter estimate for a given redundant level was assumed to be equal to the negative sum of coefficients of the other two levels (Holmes and Adamowicz, 2003). Magnitude of the coefficients reflects the relative importance (Marginal Utility) of the corresponding attribute level to the respondent.

Table 1: Attributes and levels used in the choice experiment

\begin{tabular}{|c|c|}
\hline Attribute & Levels \\
\hline 1. Improvement of cleaning & $\begin{array}{l}\text { - } \quad \text { By individuals in their premises } \\
\text { - } \quad \text { By neighbor groups in surroundings } \\
\text { - } \quad \text { By Municipality health services in } \\
\text { public places }\end{array}$ \\
\hline 2. Infrastructure provision & $\begin{array}{ll}\text { - } & \text { Efficient water supply } \\
\text { - } & \text { Efficient waste collection } \\
\text { - } & \text { Both }\end{array}$ \\
\hline $\begin{array}{l}\text { 3. Motivation of public to } \\
\text { continue control activities }\end{array}$ & $\begin{array}{l}\text { - Education and monitoring once in } \\
\text { two weeks + No spot fines } \\
\text { - } \begin{array}{l}\text { Education and monitoring once in a } \\
\text { month + Rs. } 100 \text { spot fine }\end{array} \\
\text { - } \quad \begin{array}{l}\text { Education and monitoring once in } \\
\text { three months + Rs.250 spot fine }\end{array}\end{array}$ \\
\hline $\begin{array}{l}\text { 4. WTP for control activities } \\
\text { (per household per year) }\end{array}$ & $\begin{array}{ll}\text { - } & \text { Rs.0 } \\
\text { - } & \text { Rs.100 } \\
\text { - } & \text { Rs.500 }\end{array}$ \\
\hline
\end{tabular}


49

Table 2:

A sample choice set used in the study

\begin{tabular}{lll}
\hline 1.Improvment in cleaning & \multicolumn{1}{c}{ Choice A } & \multicolumn{1}{c}{ Choice B } \\
$\begin{array}{lll}\text { By Municipality health } \\
\text { services in public } \\
\text { places }\end{array}$ & $\begin{array}{l}\text { By neighbor groups in } \\
\text { surroundings }\end{array}$ \\
$\begin{array}{l}\text { Efficient waste } \\
\text { collection }\end{array}$ & $\begin{array}{l}\text { Efficient waste } \\
\text { collection }\end{array}$ \\
$\begin{array}{l}\text { Education and monitoring } \\
\text { Spot fine }\end{array}$ & Once in 2 weeks & Once in 3 months \\
4. WTP $(\mathrm{yr})$ & $\begin{array}{l}\text { No fines } \\
\text { Rs.100 }\end{array}$ & $\begin{array}{l}\text { Rs } 250.00 \\
\text { Rs.0 }\end{array}$ \\
\hline
\end{tabular}

Choice A

Choice B

Neither

The second section of the questionnaire consists of a set of attitudinal questions which are intended to identify respondents personal views on environment related health issues. The respondents were asked to rank from a list of four problems in Sri Lanka, which they considered to be most important to immediately solve by the government.

\section{Results and Discussion}

\section{Demographic and Socio-economic Characteristics of Respondents}

Table 3 depicts the summary of the demographic and socioeconomics characteristics of the sample. As shown by the table, most of the respondents were female (64\%) and the average age was 42 years with standard deviation of 12.84. About $90 \%$ of the respondents were married while most of them had completed secondary education. Monthly income of the respondents was in the range of Rs. 4,000 to Rs. 57,000.

Table 3: Descriptive statistics of respondents

\begin{tabular}{lrrrr}
\hline Variable & Mean & Std.dev & Min. & Max. \\
\hline Age (years) & 41.57 & 12.84 & 20 & 79 \\
Education (no.of & 11.67 & 3.15 & 0 & 16 \\
years) & & & & \\
$\begin{array}{l}\text { Family income } \\
\text { (Rs./month) }\end{array}$ & 19,398 & $10,770.40$ & 4,000 & 57,000 \\
\hline $\mathrm{n}=64$ & & & & \\
\hline
\end{tabular}

\section{General Attitude of Respondents on Health Issues}

When they were asked about the priority of the issues, they have ranked health care provision as the major problem, followed by crimes and 
natural hazards. Then of the health problems, $53 \%$ of the respondents mentioned dengue as the most important communicable disease to control in Sri Lanka while $36 \%$ stated HIV. Malaria was reported as the third important disease to be prevented.

Respondents were asked to state their attitude about the current dengue control activities adopted by the KMC and their neighbors. Most of the respondents (39\%) were unsatisfied about the current dengue control activities by the KMC. There was a mixed response to the satisfaction about current dengue control activities adopted by the neighbors. Table 4 shows the major problems the respondents face when adopting dengue control activities. A majority of the respondents complained lack of support from neighbors as the major limitation followed by lack of time and lack of support from the KMC.

Table 4: $\quad$ Problems faced when adopting dengue control measures

\begin{tabular}{lc}
\hline \multicolumn{1}{c}{ Problem } & Percentage \\
\hline Lack of time & 28.1 \\
Lack of support from neighbors & 34.4 \\
Lack of efficient waste collection service & 10.9 \\
Lack of support from UC to clean public places & 20.3 \\
Lack of knowledge & 6.25 \\
\hline
\end{tabular}

\section{Results of the Estimation of Multinomial Logit Model}

According to Table 5, almost all the levels of the four environment management attributes and the alternative specific constant were statistically significant at 0.05 . The first and third levels of the attribute "Improved cleaning" were negatively significant, implying that the respondents do not prefer improved cleaning by the households in house premises and the municipality at public places as effective strategies for dengue control in the Kandy municipality.

Also the first and third levels of the attribute "Provision of infrastructure" had positive coefficients. This shows that the respondents feel these two alternatives would improve their welfare. People expect that the municipal council should use these as actions to manage environment for dengue control. Of the third level of the attribute "Motivation of public to continue environmental management for dengue control" which included a comparatively larger spot fine charged against those who mismanage the environment, the coefficient was positively significant.

The negative coefficient for peoples' willingness to pay for dengue control reflects that people do not prefer to spend their money for dengue 
control. Instead, they feel that it is the government's responsibility to bear expenses for dengue control.

Table 5: Estimations multinomial logit model

\begin{tabular}{|c|c|c|c|c|}
\hline Variable & Coefficient & $\begin{array}{l}\text { Std. } \\
\text { error }\end{array}$ & $\begin{array}{c}\mathbf{P} \\
\text { value }\end{array}$ & $\begin{array}{l}\text { MWTP } \\
\text { (Rs./ mo) }\end{array}$ \\
\hline Constant & $0.667 *$ & 0.293 & 0.023 & \\
\hline \multicolumn{5}{|l|}{ 1.Improved cleaning } \\
\hline By households in house premises & $-1.023 *$ & 0.336 & 0.002 & -1.669 \\
\hline $\begin{array}{l}\text { By resident groups in surrounding } \\
\text { areas }\end{array}$ & $2.781 *$ & - & - & 4.537 \\
\hline By municipality in public places & $-1.758 *$ & 0.246 & 0.000 & -2.868 \\
\hline \multicolumn{5}{|l|}{ 2. Infrastructure provision } \\
\hline Efficient water supply & 0.238 & 0.241 & 0.325 & 0.388 \\
\hline Efficient waste collection & $-0.889 *$ & - & - & -1.450 \\
\hline Both & 0.651 & 0.353 & 0.065 & 1.062 \\
\hline \multicolumn{5}{|l|}{ 3.Motivation } \\
\hline $\begin{array}{l}\text { Through monitoring and educating } \\
\text { once in } 2 \text { weeks }+ \text { No fines }\end{array}$ & -0.173 & 0.242 & 0.477 & -0.282 \\
\hline $\begin{array}{l}\text { Through monitoring and educating } \\
\text { once in } 4 \text { weeks + Rs. } 100 \text { spot fines }\end{array}$ & $-1.037 *$ & - & - & -1.692 \\
\hline $\begin{array}{l}\text { Through monitoring and educating } \\
\text { once in } 3 \text { months + Rs. } 250 \text { spot } \\
\text { fines }\end{array}$ & $1.21 *$ & 0.339 & 0.000 & 1.974 \\
\hline $\begin{array}{l}\text { WTP for dengue control (Rs. Per } \\
\text { household/yr) }\end{array}$ & $-0.613 *$ & 0.242 & 0.011 & - \\
\hline Log-likelihood & -34.1 & & & \\
\hline Likelihood ratio ( pseudo- $\mathrm{R}^{2}$ ) & 0.15 & & & \\
\hline
\end{tabular}

* Significant at $\alpha=0.05$

\section{Implicit Prices}

The ratio between the coefficient of a given non-monetary attribute level and the coefficient of the monetary attribute gives the implicit price or Marginal Willingness to Pay (MWTP) of that particular non-monetary attribute. MWTP is the amount of money an individual is willing to pay in order to receive more of a given attribute, holding the other attributes constant. As shown in Table 5, the public will suffer a welfare loss from policies to improve cleaning except improved cleaning by the neighbors in the surrounding areas. Among infrastructure provision options, efficient waste collection had a negative implicit value. The respondents will suffer a welfare loss if motivation of public is done without charging spot fines and if spot fines are small. Further, the imputed value increases when the value of spot fine increases. 


\section{Reason for Choice}

In the choice experiment, the reason for the choice was reported. A forth of the respondent stated they preferred improvements in the municipality health services while $22 \%$ of the respondent considered the importance of monitoring. Nineteen percent of the respondents pointed out monitoring along with legal regulations were important when making their choices. The other reasons include importance of cleaning own premises by households, importance of neighbors in controlling dengue, efficient waste collection and inability to pay big amounts for dengue control. When the respondents were asked whether they found any of the environment management attributes more important than the others. They indicated that motivation followed by improved cleaning as the most important attributes.

\section{Conclusions}

In this study environment management strategies for dengue control in $\mathrm{KMC}$, as perceived by the public, were identified using a choice experiment. These findings must be taken into account in developing policies to control dengue, as it enables getting more public support.

Almost all of the respondents mentioned during the interview, that they currently adopted dengue preventive and control measures at home and $28 \%$ of them stated that lack of time availability for them to get involve in dengue control activities. These might be the reasons for respondents to have negative preferences for policies aimed at improved cleaning by households. The majority of respondents stated that lack of support from neighbors to manage the environment is the major limitation for dengue control. Similarly, the choice experiment findings suggest that the public has the highest marginal willingness to pay for improved cleaning by the neighbors.

According to the Preventive and Promotive Health Unit, Kandy, most of the areas at high risk of dengue in Kandy lack efficient water supply and water storing tanks have been identified as a major mosquito breeding place. The study reveals that the public prefers provision of an efficient water supply. The reason for positive public preference for efficient water supply in the choice experiment is that people agree that absence of a dependable water supply in most of the high risk areas in the municipality is one major reason for dengue spread. Therefore, policies should be formulated and programmes should be implemented to ensure these services be efficient.

The most important attribute in the choice experiment was to motivate the public to manage the environment properly. The public does not prefer when motivation is done only through monitoring and educating by the 
health personnel once in two weeks. Instead, they prefer if the public is motivated through monitoring and education along with charging spot fines against those who do not adopt health measures to control dengue. The health unit of the KMC educates and monitors people in high risk areas and in certain situations a Rs.100.00 fine is charged against law breakers. However, the people are not satisfied about the current level of these activities. They prefer further improvements in motivation, mainly the policies which enable charging larger fines against law breakers as they believe larger fines can change people's behavior. Therefore, policies and legal regulations must be modified accordingly.

\section{References}

Adamowicz W., J. Louviere and M. Williams (1994).Combining Revealed and Stated Preference Methods for Valuing Environmental Amenities. Journal of Environmental Economics and Management, 26: 271-292.

Adamowicz, W., P. Boxall, M. Williams and J. Louviere (1998). Stated Preference Approaches for Measuring Passive Use Values: Choice Experiments and Contingent Valuation. American Journal of Agricultural Economics, 80(1): 64-75.

Bateman, I.J., R.T. Carson, B. Day, M. Hanemann, N. Hanley, T. Hett, M. Jones-Lee, G. Loomes, S. Mourato, E. Ozdemiroglu, D. Pearce, R. Sugden and J. Swanson (2002). Economic Valuation with Stated Preference Techniques: In, E. Elgar (ed.), A Manual. UK: Cheltenham.

Boxall, P. and W. Adomowicz (2002). Understanding Heterogeneous Preferences in Random Utility Models: A Latent class Approach. Environmental and Resource Economics, 23: 421-446.

Gunatilake, H.M. (2003). Choice Experiments. In: Environmental Valuation: Theory and Applications. Sri Lanka: Postgraduate Institute of Agriculture.

Hanley N., R.E. Wright and G. Koop (2002). Modeling Recreation Demand Using Choice Experiments: Climbing in Scotland. Environmental and resource Economics, 22: 449-466.

Holmes T.P. and W.L. Adamowicz (2003). Attribute-Based Methods. In, P.A. Champ, K.J. Boyle and T.C. Brown (Eds.), A Primer on non-Market Valuation. Netherlands: Dordrecht. 
Lancaster, K.J. (1966). A New Approach to Consumer Theory. Journal of Political Economics, 74: 132-157.

Louviere J., J. Hall, R. Vivey and M. Hans (2004). Using Stated Preference Choice Modeling to Evaluate Health Care Programs. Journal of Business research, 57: 1026-1032.

McFadden, D. (1973). Conditional Logit Analysis of Qualitative Choice behavior. In, P. Zarembka (ed.), Frontiers in Econometrics. New York: Academic Press.

Morrison, M., J. Bennet, R. Blamey and J. Louviere (2002). Choice Modeling and tests of Benefit Transfer. American Journal of Agricultural Economics, 84: 161-170.

National Plan of Action 2005-2009 (2006). Epidemiology Unit, Ministry of Health, Sri Lanka. [cited on 11 November 2006]. <www.health.gov.lk>

Thurstone, L. (1927). A Law of Comparative Judgment. Psychological Review, 34: 273-286.

United Nations Environment Programme (2005). Environment and Health: New Insights into Spread of Infectious diseases. [cited on 13 November 2006]. 〈www.unis.unvienna.org/pdf/environment.pdf> 